\title{
Prevalence of malnutrition, acute respiratory infections and diarrhoea in children aged 1-5 years in urban slums of Puducherry, South India
}

\author{
Ravi Prakash Upadhyay ${ }^{\text {* }}$, Palanivel Chinnakali ${ }^{2}$, Meenakshi Bhilwar ${ }^{1}$, \\ Balaji Krishnan $^{3}$, Vaman Kulkarni ${ }^{4}$, Arti Gupta ${ }^{5}$, S. A. Rizwan ${ }^{5}$
}

\begin{abstract}
${ }^{1}$ Department of Community Medicine, Vardhman Mahavir Medical College \& Safdarjung Hospital, New Delhi, India ${ }^{2}$ Department of Preventive and Social Medicine, Jawaharlal Institute of Postgraduate Medical Education and Research, Puducherry, India

${ }^{3}$ Undergraduate student, Indira Gandhi Medical College and Research Institute, Puducherry, India

${ }^{4}$ Department of Community Medicine, Kasturba Medical College, Mangalore, Karnataka, India

${ }^{5}$ Junior Resident, Center for Community Medicine, All India Institute of Medical Sciences, New Delhi, India
\end{abstract}

Received: 18 January 2015

Accepted: 23 January 2015

\section{*Correspondence:}

Dr. Ravi Prakash Upadhyay,

E-mail: ravi.p.upadhyay@ gmail.com

Copyright: (C) the author(s), publisher and licensee Medip Academy. This is an open-access article distributed under the terms of the Creative Commons Attribution Non-Commercial License, which permits unrestricted non-commercial use, distribution, and reproduction in any medium, provided the original work is properly cited.

\section{ABSTRACT}

Background: Aim of current study was to document the prevalence of malnutrition, burden of acute respiratory and diarrhoeal diseases in children aged 1-5 years in urban slums of South India.

Methods: A cross-sectional study was conducted in Villianur municipal area of Puducherry district, South India. A semi-structured pretested interview schedule was used to collect information on demographic details of the family, episodes of ARI and diarrhoea and health seeking behaviour. Anthropometric measurements were also done.

Results: A total of 242 children were studied. The prevalence of stunting and wasting was $25.2 \%$ and $12.2 \%$ respectively. Nearly $60 \%$ reportedly had at least one episode of ARI (144/242) and one-fourth had at least one episode of diarrhoea $(60 / 242 ; 24.8 \%)$ in the last three months prior to the interview. There were no sex based differences in the treatment seeking practices.

Conclusions: Considerable burden of malnutrition, ARI and diarrhoea exists in children of this urban slum. Health seeking behaviour was appropriate.

Keywords: Under-five, Urban slum, Malnutrition, Acute respiratory infection, Diarrhoea, South India

\section{INTRODUCTION}

Under-nutrition is a wide spread form of malnutrition in developing countries and is the major factor in childhood mortality and morbidity. ${ }^{1}$ With rapid urbanisation, about one fourth of the urban population in India is forced to reside in urban slums. ${ }^{2}$ Non availability of the basic human necessities in the urban slums adversely affects the growth and nutritional status of the slum population. Urban slum dwellers are exposed to poor environmental conditions (overcrowding, poor quality drinking water and sanitation, no removal of waste etc.). ${ }^{3}$ Ignorance and difficult conditions of life in the slums are likely to result in improper food habits, low health care use and inappropriate hygiene awareness. ${ }^{3}$ The situation is further worsened due to lack of necessary health centres, medicines, and health care personnel. ${ }^{4}$

Under-five children, being the most vulnerable segment, are at greater risk of malnutrition mainly because of deficient dietary intake and high load of infections. These children are susceptible to vicious cycle of malnutrition and infection as well. 
As per National Family Health Survey-3, proportion of children under three years who were stunted was higher among urban poor than non-urban poor $(54.2 \%$ vs. $33.3 \%) .{ }^{5}$ Similarly, the proportion of children under three years who were underweight was higher among urban poor than non-urban non poor $(47.1 \%$ vs. $26 \%) .{ }^{5}$ Chronic under nutrition in childhood is linked to slower cognitive development and serious health impairments later in life that reduce the quality of life of individuals. ${ }^{6-8}$ In this respect, understanding the nutritional status of children has far-reaching implications for the better development of future generations.

Acute Respiratory Infection (ARI), especially pneumonia is an important cause of morbidity and mortality in children worldwide..$^{9-11}$ The developing world accounts for a substantial percentage of the global ARI morbidity and mortality. ${ }^{10,11}$ Also, globally, each year, an estimated 2.5 billion cases of diarrhoea occur among children under five years of age and more than half of these cases occur in Africa and South Asia where episodes of diarrhoea are more likely to result in death or other severe outcomes. $^{12,13}$

Although the prevalence of acute respiratory and diarrhoeal diseases in under five in India have been adequately studied, most of the available data are institution-based and there is still a paucity of community-based studies, mores so from the slum population. Moreover, malnutrition in children has often been implicated in the adverse outcomes due to ARI and diarrhoea but there is a lack of sizeable literature documenting its prevalence from slums of India. Against this backdrop the current study was planned with the objective(s) to document the prevalence of malnutrition, burden of acute respiratory and diarrhoeal diseases and the treatment care seeking behaviour of the care givers in urban slums of south India.

\section{METHODS}

\section{Study setting and participants}

A community based cross-sectional study was conducted in Villianur Municipal area of Puducherry district. Villianur is a town in the union territory of Puducherry, India, located at a distance of 9 kilometres south from the Puducherry municipality. According to the 2001 census, it had a population of 104000 . There is a primary health centre catering to the Villianur area. Children aged 12-60 months who were residing in the area for past six months were included in the study. For documenting the health care seeking behaviour, family members (preferably the mother/father of the child) were interviewed.

\section{Sample size and sampling design}

The sample size for the current study was calculated using the formula: $\mathrm{N}=4 \mathrm{pq} / \mathrm{d} 2$, where $\mathrm{P}$ is the prevalence of malnutrition and $\mathrm{q}$ is the complement of $\mathrm{p}$. Considering the prevalence of stunting among under-five children as $63 \%,{ }^{14}$ assuming an alpha error of 0.05 and relative precision of $10 \%(\mathrm{~d}=$ relative precision $)$, the required sample size was calculated to be 235 . A total of 13 urban slums were identified and surveyed with the help of health workers. All houses in the slums were visited. Since the population of these slums was small (each of about 700 population of 100 to 150 families), all eligible children in the visited houses were included in the study.

\section{Data collection}

House to house visits were made by trained data collectors. Anthropometric measurements, following standard guidelines, were done to collect information on nutrition status of the eligible children.

Children under five years in the selected households were studied by measuring the height, weight, and mid arm circumference. Weight measurements were taken in a portable digital platform weighing balance. The scale was adjusted to zero before each measurement. Weight was recorded to the nearest $0.1 \mathrm{~kg}$. Height was measured to the nearest $0.5 \mathrm{~cm}$ using a measuring tape fixed vertically on a smooth wall perpendicular to the ground. Each reading was taken twice to ensure correctness of the measurement and to minimize intrapersonal errors.

Mid Upper Arm Circumference (MUAC) was measured at the midpoint between acromion and olecranon process in the right hand. The data collectors were trained to take these measurements by the study investigators during pretesting in the community itself.

A semi-structured pretested interview schedule was used to collect information on demographic details of the family, birth order of the child, episodes of ARI and diarrhoea (in the last three months from the time of interview) and health seeking behaviour. The study was approved by the ethics committee of Indira Gandhi medical college and research institute, Puducherry, India.

As the information on ARI and diarrhoea was reported by the mothers/care givers, the operational definition of these were taken as that defined by IMNCI. The child was considered to have "diarrhoea" if the mothers reported that the stools had changed from usual pattern and were many and watery (more water than faecal matter).

The child was considered to have acute respiratory infection if the mother reported the child to have cough and difficulty in breathing. Mothers were also asked if the mother had noticed a harsh sound while the child was breathing in (to check for stridor). Medical reports/doctor's prescriptions were also looked, depending upon their availability with the mother, to decide if the child had diarrhoea or respiratory infection. 


\section{Statistical analysis}

Data collected was entered in the Microsoft excel spreadsheet and analysed with SPSS version 17.0 (Chicago, IL, USA). 'WHO 2006 Growth standards' was used for classifying the malnutrition. $\mathrm{Z}$ scores of weight for age, height for age and weight for height were calculated. Wherever applicable, proportions and mean (SD) were calculated. Chi square test was used to compare proportions. Student's t-test was used to compare the means. For statistical significance, $\mathrm{P}$ value of $<0.05$ was considered.

\section{RESULTS}

\section{Socio-demographic profile}

A total of 242 children in the age group of 1-5 years were included in the study. Socio-demographic characteristics are given in Table 1 . Nearly $57 \%$ of children were males. More than half $(55.8 \%)$ of the children were of first birth order. The mean age (in years) of the children included in the study was $2.8 \pm 1.1$. Around one-fourth $(23.9 \%)$ of children's father were working as daily labourers whereas $36 \%$ had a permanent employment. More than half (55\%) of mothers were educated till middle or high school. Majority (79\%) of the children were from a family with monthly family income ranging from $\$ 3000-\$ 10000$ (55-185 USD). The mean family income of the children included in the study was $\$ 7005.9 \pm 4211.8(130 \pm 78$ USD).

\section{Prevalence of malnutrition}

Based on WHO 2006 growth standards, the prevalence of "any" under nutrition (weight for age $\leq 2 \mathrm{SD}$ ) was $10.1 \%$. The overall prevalence of stunting (height for age $\leq 2 \mathrm{SD}$ ) was $25.2 \%$ and wasting (weight for height $\leq 2 \mathrm{SD}$ ) was $12.2 \%$. Prevalence of "severe" under nutrition (weight for age $\mathrm{Z}$ score $\leq 3 \mathrm{SD}$ ) was $3.4 \%$. Severe wasting (weight for height $\mathrm{Z}$ score $\leq 3 \mathrm{SD}$ ) was found to be in $4.6 \%$ of children and severe stunting (height for age $\mathrm{Z}$ score $\leq 3$ $\mathrm{SD})$ was found in $13.9 \%$ of children.

\section{Prevalence and treatment seeking for acute respiratory infections (ARI)}

Out of the total children studied, nearly $60 \%$ of them were reported to have at least one episode of ARI $(144 / 242)$ in the last three months prior to the interview. Majority of them had a single episode $(93.1 \% ; 134 / 144)$ whereas those with two and three episodes were $4.7 \%$ and $2.1 \%$ respectively. Most of the ill children were taken first to private health care facility/practitioners (64.6\%; 93/144) whereas around one-fourth were first taken to government health facility $(29.9 \%$; 43/144). Traditional healers and pharmacists were preferred first in $2.1 \%$ and $1.4 \%$ children respectively. There were no statistically significant differences, based on the sex of the child; in terms of the place from where treatment was sought.
Similar proportions of ill male and female children were taken to a private health facility $(60 \%$ vs. $70.3 \% ; \mathrm{P}=$ $0.47)$ and government health facility $(33.8 \%$ vs. $25 \% ; \mathrm{P}=$ $0.47)$. The mean amount spent on treatment was $\$ 342.1$ \pm 201.9 . The amount spent on male and female children was $\$ 350.2 \pm 210.4$ and $\$ 334 \pm 196.2$ respectively and the difference was not statistically significant $(\mathrm{P}=0.71)$.

Table 1: Frequency distribution of key variables among the study population ( $\mathrm{N}=242)$.

\begin{tabular}{|ll|}
\hline Variables & $\mathbf{n}(\%)$ \\
\hline Sex of the child & $137(56.6)$ \\
\hline Male & $105(43.4)$ \\
\hline Female & \\
\hline Age (months) & $55(22.7)$ \\
\hline $12-23$ & $56(23.1)$ \\
\hline $24-35$ & $60(24.8)$ \\
\hline $36-47$ & $71(29.4)$ \\
\hline $48-60$ & $135(55.8)$ \\
\hline Birth order & $99(40.9)$ \\
\hline 1 & $8(3.3)$ \\
\hline 2 & \\
\hline 3 & $16(6.6)$ \\
\hline Mother's education & $133(55)$ \\
\hline Up to primary school & $40(16.5)$ \\
\hline Middle and high school & $53(21.9)$ \\
\hline Higher secondary school & \\
\hline Graduation and above & $14(5.8)$ \\
\hline Father's education & $118(48.7)$ \\
\hline Up to primary school & $43(17.8)$ \\
\hline Middle and high school & $67(27.7)$ \\
\hline Higher secondary school & \\
\hline Graduation and above & $88(36.4)$ \\
\hline Father's occupation* & $96(39.7)$ \\
\hline Permanent job & $58(23.9)$ \\
\hline Temporary job & $213(88)$ \\
\hline Daily wage worker & $16(6.6)$ \\
\hline Religion & $13(5.4)$ \\
\hline Hindu & $8(3.3)$ \\
\hline Christian & $192(79.3)$ \\
\hline Muslim & $12(5)$ \\
\hline Monthly family income (in $\$ ; ~ U S D) * * 4$ \\
\hline$<3000$ (<55 USD) & \\
\hline 3000-10000 (55-185 USD) & \\
\hline$>10000-20000 ~(>185-370 ~ U S D)$ \\
\hline$>20000$ (>370 USD) & $30(12)$ \\
\hline & \\
\hline
\end{tabular}

*Permanent job includes government teacher/professor/clerical job, health assistant, firm manager, software engineer, police etc.; Temporary job includes taxi driver, sales executive, mechanic, fisherman etc.; $* * 1 \mathrm{USD}=\$ 54$ (as on 10.02.2013)

\section{Prevalence \& treatment seeking for diarrheal episode(s)}

Around one-fourth of the children had at least one episode of diarrhoea $(60 / 242 ; 24.8 \%)$. Out of them, 
$78.4 \%$ (47/60) had one, $13.3 \%$ (8/60) had two and $8.3 \%$ $(5 / 60)$ had three episodes of diarrhoea respectively. All of the ill children received "any kind" of treatment be it home management or seeking care outside home. Oral rehydration solution was given in $92 \%$ of the ill children. Private health care practitioners/facility $(46.7 \% ; 28 / 60)$ followed by government health facility $(23.3 \%$; 14/60) were the most preferred first point for care seeking. Home treatment was practiced as the sole mode of management in $21.6 \%(13 / 60)$ children whereas pharmacists were consulted at the first instance in $8.3 \%$ (5/60). Sex of the child did not influence the place of treatment seeking as similar proportions of male and female child were taken to a government health facility (19.2\% vs. $35.3 \% ; \mathrm{P}=0.39)$ and private health care practitioners/facility $(69.2 \%$ vs. $52.9 \%$; $\mathrm{P}=0.39)$. The mean amount spent on treatment was \$239 \pm 136.2 . There was no statistically significant difference in the amount spent on treatment based on the sex of the child (male vs. female; $241.4 \pm 166.7$ vs. $236.3 \pm 128.7$; $\mathrm{P}=$ 0.93).

\section{DISCUSSION}

The current study was undertaken to document the prevalence of malnutrition among child of urban slums in Puducherry, South India. As malnutrition is often linked to low immunity and consequently the chances of children being affected by acute respiratory infections and diarrheal illness becomes high, the study also aimed to report the prevalence of these among the children studied. Our study showed lower prevalence of undernutrition, wasting and stunting when compared to the National Family Health Survey-3 (NFHS-3) urban poor indicators. In the current study the prevalence of undernutrition, wasting and stunting was $10.1 \%, 12.2 \%$ and $25.2 \%$ respectively as against $47.1 \%, 20.8 \%$ and $54.2 \%$ for the urban poor from the NFHS-3 data. ${ }^{5}$

In the present study, a high proportion of children were affected by acute respiratory infections in the last three months prior to the interview. More than half $(60 \%)$ had an episode of ARI in last three months. Out of them, majority (93.4\%) reported only a single episode. This calls for more research to look into the factors responsible for such a high incidence of ARI. Other studies conducted in different parts of the country have reported a comparatively lesser rates. A cross-sectional survey was carried in urban slum of trans-Yamuna region of Delhi, where a total of 1307 under five children were studied. ${ }^{15}$ Out of these, $14.6 \%$ had an attack of ARI in the preceding two weeks. Another study undertaken in urban and rural areas of West Tripura district found monthly incidence of ARI in children under-five years of age, as $23 \%$ and $17 \%$ respectively. ${ }^{16}$ The reported lower incidence(s) of ARI by these studies compared to the current study might be due to shorter recall period considered in these studies. It is worthwhile to note that, in the current study, majority of ill under-five children were taken to either private or public health care facility with only a small percentage of them taken to traditional healers/pharmacists. Moreover, no significant sex based differences in care seeking was obtained. These findings seem to be surprising in an urban slum set up as the health care seeking for childhood illnesses is often reported to be inadequate and sex based bias frequent in previous literature, irrespective of the place of study i.e. urban, peri-urban, rural. ${ }^{17-20}$

Around one quarter of the study participants, in the current study, had an episode of diarrhoea in last three months. Nearly half $(46.7 \%)$ of parents visited private facility and one fifth $(23.3 \%)$ visited government health facilities for seeking care for their child. Oral Rehydration Salt (ORS) was administered by more than 90 percent of the parents to their child suffering from diarrhoea. This reported prevalence of diarrhoea $(36 \%)$ was comparable to a study carried out in an urban slum of Aligarh, Uttar Pradesh in 2009. ${ }^{21}$ More than three-fifth of the children with ARI and all the children with diarrhoea received treatment of "any kind" which points towards the fact that the care givers were probably aware that these conditions required attention. Also, traditional healers and pharmacists were consulted by very few, though government health facilities were not the place of choice. More research is required to understand the reasons for preference for private over government health care facilities.

The study has its limitations as well. Firstly, the number of episodes of ARI and diarrhoea were self-reported and there could be a possibility of recall bias. Secondly, no information was collected on the nature of home treatment given to the child with diarrhoea. This is important as various food taboos exist in the community, especially in context of feeding of the child during diarrhoeal illness. Moreover, home treatment could result in delay in receiving adequate care from a health care facility. Thirdly, additional information on diet like calories consumed, dietary diversification would have better explained the nutritional status of the children. Also, the study was done in only municipal area of Puducherry and extrapolation of the results to other areas is not possible.

\section{CONCLUSION}

Considerable burden of severe malnutrition, ARI and diarrhoea exists in children of urban slum and programs focussing on poverty reduction, environmental hygiene and sanitation could improve the situation. Health seeking behaviour for ARI and diarrhoea was good in this urban slum population.

\section{Funding: No funding sources Conflict of interest: None declared}

Ethical approval: The study was approved by the institutional ethics committee of Indira Gandhi medical college and research institute, Puducherry, India 


\section{REFERENCES}

1. Pelletier DL, Frongillo EA. Changes in child survival are strongly associated with changes in malnutrition in developing countries. J Nutr. 2003;133(1):107-19.

2. Registrar General of India, 2006. Report of technical group on population projection, 20012026. Available at: https://nrhmmis.nic.in/Part\%20B\%20Demographic\%20and\%20 Vital\%20Indicators/Population\%20Projection\%20R eport\%202006\%20by\%20RGI.pdf.

3. Viswanathan V, Tharkar S. Can the divide be bridged? Overview of life in urban slums in India. Indian J Community Med. 2010;35(1):198-9.

4. Agarwal S, Satyavada A, Kaushik S, Kumar R. Urbanization, urban poverty and health of the urban poor: status, challenges and the way forward. Demography India. 2007;36(1):121-34.

5. IIPS. National family health survey-3 (2005-2006). In: IIPS, eds. IIPS Survey. Mumbai, India: International Institute of Population Sciences; 2007.

6. Scrimshaw NS. The consequences of hidden hunger for individuals and societies. Food Nutr Bull. 1994;15:2-23.

7. Lee JW. Child survival: a global health challenge. Lancet. 2003;362(9380):262.

8. Srivastava A, Mahmood SE, Srivastava PM, Shrotriya VP, Kumar B. Nutritional status of school-age children: a scenario of urban slums in India. Arch Public Health. 2012;70(1):8.

9. WHO. Media centre-Fact sheet $\mathrm{N}^{\circ} 331$ : Pneumonia, 2013. Available at: http://www.who.int/mediacentre/factsheets/fs331/en /. Accessed November 2014.

10. Black RE, Cousens S, Johnson HL, Lawn JE, Rudan I, Bassani DG, et al. Global, regional, and national causes of child mortality in 2008: a systematic analysis. Lancet. 2010;375:1969-87.

11. United Nations Children's Fund (UNICEF). Pneumonia and diarrhoea: tackling the deadliest diseases for the world's poorest children, June 2012. Available

at: http://www.unicef.org/media/files/UNICEF_P_D_c omplete_0604.pdf. Accessed 13 August 2013.

12. The United Nations Children's Fund (UNICEF)/World Health Organization (WHO).
Diarrhoea: why children are still dying and what can be done, 2009. Available at: http://www.unicef.org/media/files/Final_Diarrhoea_ Report_October_2009_final.pdf. Accessed 20 August 2013.

13. Boschi-Pinto C, Velebit L, Shibuya K. Estimating child mortality due to diarrhoea in developing countries. Bull World Health Organ. 2008;86:710-7.

14. Awasthi S, Pande VK. Prevalence of malnutrition and intestinal parasites in preschool slum children in Lucknow. Indian Pediatr. 1997;34(7):599-605.

15. Gupta N, Jain SK, Ratnesh, Chawla U, Hossain S, Venkatesh S. An evaluation of diarrheal diseases and acute respiratory infections control programmes in a Delhi slum. Indian J Pediatr. 2007;74(5):471-6.

16. Deb SK. Acute respiratory disease survey in Tripura in case of children below five years of age. J Indian Med Assoc. 1998;96(4):111-6.

17. Upadhyay RP, Rai SK, Anand K. Community neonatal practices and its association with skilled birth attendance in rural Haryana, India. Acta Paediatr. 2012;101(12):e535-9.

18. Malhotra N, Upadhyay RP. Why are there delays in seeking treatment for childhood diarrhoea in India? Acta Paediatr. 2013 Sep;102(9):e413-8.

19. Willis JR, Kumar V, Mohanty S, Singh P, Singh V, Baqui $\mathrm{AH}$, et al. Gender differences in perception and care seeking for illness of new-borns in rural Uttar Pradesh, India. J Health Popul Nutr. 2009;27(1):62-71.

20. Pandey A, Sengupta PG, Mondal SK, Gupta DN, Manna B, Ghosh S, et al. Gender differences in healthcare-seeking during common illnesses in a rural community of West Bengal, India. J Health Popul Nutr. 2002;20(4):306-11.

21. Shah MS, Ahmad A, Khalique N, Afzal S, Ansari MA, Khan Z. Home-based management of acute diarrhoeal disease in an urban slum of Aligarh, India. J Infect Dev Ctries. 2012;6(2):137-42.

DOI: $10.5455 / 2349-3291 . i j c p 20150209$

Cite this article as: Upadhyay RP, Chinnakali $\mathrm{P}$, Bhilwar M, Krishnan B, Kulkarni V, Gupta A, Rizwan SA. Prevalence of malnutrition, acute respiratory infections and diarrhoea in children aged 1-5 years in urban slums of Puducherry, South India. Int J Contemp Pediatr 2015;2:37-41. 